\title{
PENURUNAN MODEL BLACK-SCHOLES DENGAN METODE BINOMIAL UNTUK SAHAM TIPE EROPA
}

\author{
LINA MUAWANAH NASIR \\ Program Studi Matematika, \\ Fakultas Matematika dan Ilmu Pengetahuan Alam, Universitas Andalas, \\ Kampus UNAND Limau Manis Padang, Indonesia, \\ muawanahnasirlina@yahoo.co.id
}

\begin{abstract}
Abstrak. Opsi Eropa adalah suatu kontrak keuangan yang memberikan hak (bukan kewajiban) kepada pemegang opsi untuk membeli atau menjual sejumlah aset tertentu pada waktu jatuh tempo dengan harga pelaksanaan yang sudah ditentukan. Harga opsi saham dapat ditentukan melalui model Black-Scholes yang mengasumsikan bahwa opsi yang digunakan adalah opsi tipe Eropa. Untuk panjang periode yang sangat pendek, metode binomial yang merupakan model penentuan harga opsi lainnya, memberi hampiran diskret untuk proses harga kontinu dibawah model Black-Scholes. Oleh karena itu, model Black-Scholes dapat diturunkan dari metode binomial. Model BlackScholes dipengaruhi oleh faktor-faktor seperti harga saham, harga pelaksanaan, suku bunga bebas resiko, waktu jatuh tempo, dan volatilitas. Hasil pembahasan pada Intel Corporation menunjukkan pembeli opsi call memperoleh keuntungan maksimum pada harga pelaksanaan 22.5 dollar, dan pembeli opsi put memperoleh keuntungan maksimum pada harga pelaksanaan 26.5 dollar.
\end{abstract}

Kata Kunci: Opsi, metode Binomial, model Black-Scholes

\section{Pendahuluan}

Dalam dunia keuangan investor memiliki pilihan untuk membeli aset yaitu membeli aset yang diperdagangkan secara langsung dipasar keuangan atau membeli derivasi/turunan dari aset tersebut. Aset yang secara keseluruhan maupun sebagian nilainya merupakan turunan dari aset lain, disebut dengan aset derivatif. Beberapa produk derivatif antara lain : kontrak berjangka (future contract), kontrak forward dan kontrak opsi.

Opsi berdasarkan hak yang diberikan kepada pemegangnya dibedakan menjadi opsi call dan opsi put. Opsi call memberikan hak kepada pembeli untuk membeli aset tertentu dengan jumlah tertentu pada harga yang telah ditentukan selama periode waktu tertentu pula. Sedangkan opsi put memberikan hak kepada pembeli untuk menjual aset tertentu dengan jumlah tertentu pada harga yang telah ditentukan selama periode waktu tertentu pula. Sedangkan opsi berdasarkan periode waktu penggunaannya dibedakan menjadi opsi tipe Eropa dan opsi tipe Amerika. Opsi yang dapat dilaksanakan kapan saja sampai tanggal jatuh temponya disebut dengan opsi tipe Amerika. Opsi yang dapat dilaksanakan hanya pada saat tanggal jatuh tempo disebut dengan opsi tipe Eropa [3].

Metode penetapan harga opsi saham secara analitik dirumuskan oleh Fisher 
Black dan Mayor Scholes pada tahun 1973 yang dikenal dengan model BlackScholes. Model Black-Scholes menggunakan beberapa asumsi, yaitu opsi yang digunakan adalah opsi tipe Eropa, volatilitas (ukuran perubahan harga saham) bersifat konstan selama usia opsi, terdapat suku bunga bebas resiko, proses acak dalam memperoleh harga saham, saham yang digunakan tidak memberikan dividen serta tidak terdapat pajak dan biaya transaksi [4].

Selain itu, penentuan harga opsi saham melalui pendekatan numerik salah satunya adalah dengan menggunakan metode binomial. Metode binomial dikembangkan oleh Cox, Ross dan Rubinstein (CRR) pada tahun 1979 dengan mengasumsikan bahwa dalam suatu interval waktu, harga saham akan naik sebesar faktor $u(u p)$ dan akan turun sebesar faktor $d$ (down) karena dipengaruhi oleh faktor suku bunga. CRR juga mempertimbangkan bahwa pergerakan harga saham juga dipengaruhi oleh faktor volatilitas yang berarti model binomial memberi hampiran diskret untuk proses harga kontinu dibawah model Black-Scholes.

Oleh karena itu, dalam paper ini akan dilakukan penurunan model Black-Scholes menggunakan metode binomial. Adapun yang menjadi tujuan penulisan ini adalah untuk mengkaji model Black-Scholes pada opsi call dan opsi put tipe Eropa serta menghitung harga opsi call dan opsi put tersebut pada data saham, sehingga dapat dicari besarnya laba (rugi) yang akan diterima pembeli dan penjual opsi. Penulisan ini hanya dibatasi pada penurunan model Black-Scholes dengan metode binomial, serta penentuan harga opsi call dan opsi put tipe Eropa yang menggunakan data harga penutupan saham Intel Corporation selama satu tahun.

\section{Perubahan Harga Saham dengan Metode Binomial}

Perubahan harga saham terhadap waktu dapat diilustrasikan seperti berikut.

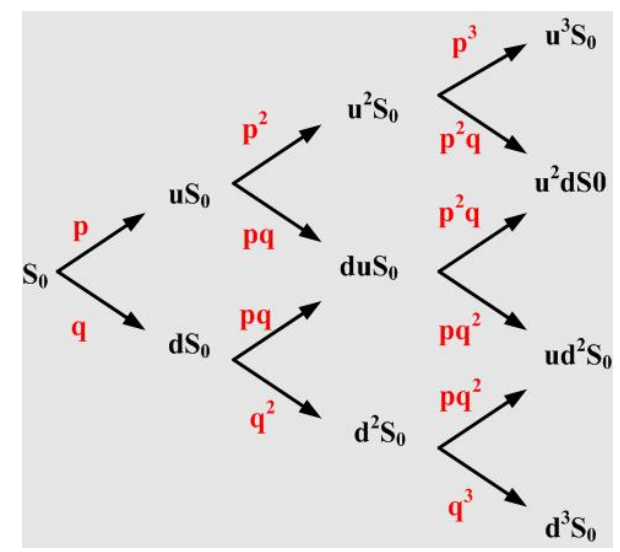

Gambar 1. Pohon Binomial Harga Saham dari 1 Periode sampai 3 Periode

Berdasarkan Gambar 1, harga saham pada waktu jatuh tempo $T$ dapat ditulis menjadi

$$
S_{T}=S_{0} u^{j} d^{(n-j)} ; j=0,1,2, \ldots, n
$$


dengan fkp dari harga saham pada waktu jatuh tempo $T=1$ adalah

$$
f\left(S_{T}\right)= \begin{cases}p & ; \text { jika saham saat } S_{T} \text { bernilai } S_{T}(u) \\ q & ; \text { jika saham saat } S_{T} \text { bernilai } S_{T}(d) .\end{cases}
$$

\section{Model Cox Ross Rubinstein (CRR)}

Berdasarkan pohon binomial, nilai ekspektasi harga saham model binomial pada $T=1$ adalah

$$
\begin{aligned}
E\left[S_{1}\right] & =\sum_{\forall S_{1}} S_{1} f\left(S_{1}\right) \\
& =u S_{0} p+d S_{0} q .
\end{aligned}
$$

Sedangkan nilai ekspektasi model kontinu

$$
S_{0} e^{r \Delta t}=u S_{0} p+d S_{0} q,
$$

jika kedua ruas nilai ekspektasi model kontinu dibagi $S_{0}$ dan nilai ekspektasi harga saham model binomial pada saat $S_{0}=1$, maka diperoleh

$$
\begin{gathered}
E\left[S_{T}\right]=p u+q d=e^{r \Delta t} \\
\operatorname{Var}\left[S_{T}\right]=p q(u-d)^{2} .
\end{gathered}
$$

Menentukan tingkat kenaikan harga saham $u$ dan penurunan harga saham $d$ dapat diperoleh dari persamaan (2.1). Peluang mendapatkan $u$ untuk setiap satu periode $\Delta t$ adalah $p$, artinya peubah acak $J$ berdistribusi binomial dengan parameter $n$ dan $p$, sehingga

$$
E(J)=n p \quad \text { dan } \quad \operatorname{Var}(J)=n p q .
$$

Dalam [1], nilai ekspektasi dan variansi return saham adalah $\mu T$ dan $\sigma^{2} T$, maka diperoleh

$$
u=e^{\sigma \sqrt{\Delta t}} \text { dan } \quad d=e^{-\sigma \sqrt{\Delta t}} .
$$

Nilai peluang resiko netral $p$ dan $q$ ditentukan berdasarkan persamaan (3.1), kemudian dengan mensubstitusi nilai $u$ dan $d$ maka diperoleh

$$
p=\frac{e^{r \Delta t}-e^{-\sigma \sqrt{\Delta t}}}{e^{\sigma \sqrt{\Delta t}}-e^{-\sigma \sqrt{\Delta t}}} \quad \text { dan } \quad q=\frac{e^{\sigma \sqrt{\Delta t}}-e^{r \Delta t}}{e^{\sigma \sqrt{\Delta t}}-e^{-\sigma \sqrt{\Delta t}}} .
$$

Sehingga $p$ dan $q$ merupakan ukuran peluang baru yang disebut sebagai peluang resiko netral (risk-neutral probability).

Selanjutnya akan ditentukan model harga opsi model binomial, yang terdiri dari 1 periode sampai $n$ periode. Pembentukan model dilakukan melalui replikasi portofolio yaitu suatu portofolio yang nilainya diakhir periode akan sama persis dengan kewajiban penerbit opsi diakhir periode. Replikasi portofolio terdiri atas saham sebanyak $\Delta_{0}$ lembar serta tabungan atau pinjaman sebanyak $\Psi$. Nilai awal opsi call dapat ditulis

$$
V_{0}=\Delta_{0} S_{0}+\Psi
$$

Perhatikan nilai portofolio satu periode berikut 


$$
\begin{aligned}
& \Delta_{0} S_{0} u+\Psi e^{r \Delta t}=f_{1}(u) \\
& \Delta_{0} S_{0} d+\Psi e^{r \Delta t}=f_{1}(d)
\end{aligned}
$$

diperoleh

$$
\Delta_{0}=\frac{f_{1}(u)-f_{1}(d)}{S_{0} u-S_{0} d} \quad \text { dan } \quad \Psi=e^{-r \Delta t} \frac{u f_{1}(d)-d f_{1}(u)}{u-d} .
$$

Kemudian substitusikan nilai $\Delta_{0}$ dan $\Psi$ ke persamaan (3.3), didapat model opsi call binomial satu periode

$$
V_{0}=e^{-r \Delta t}\left[p f_{1}(u)+q f_{1}(d)\right] .
$$

Proses yang sama akan menghasilkan model binomial opsi call dua periode sebagai berikut

$$
V_{0}=e^{-r 2 \Delta t} \sum_{j=0}^{2}\left(\begin{array}{l}
2 \\
j
\end{array}\right) p^{j} q^{2-j} \max \left\{u^{j} d^{2-j} S_{0}-K, 0\right\} .
$$

Secara umum harga opsi call untuk $n$ periode pada waktu $n \Delta t=T$ akan diperoleh

$$
V_{0}=e^{-r n \Delta t} \sum_{j=0}^{n}\left(\begin{array}{l}
n \\
j
\end{array}\right) p^{j} q^{n-j} \max \left\{u^{j} d^{n-j} S_{0}-K, 0\right\} .
$$

Begitu juga untuk opsi put, secara umum harga opsi untuk $n$ periode pada waktu $n \Delta t=T$ akan diperoleh

$$
P_{0}=e^{-r n \Delta t} \sum_{j=0}^{n}\left(\begin{array}{l}
n \\
j
\end{array}\right) p^{j} q^{n-j} \max \left\{K-u^{j} d^{n-j} S_{0}, 0\right\} .
$$

\section{Penurunan Model Black-Scholes untuk Opsi Eropa}

Terlebih dahulu diturunkan model Black-Scholes opsi call tipe Eropa melalui persamaan (3.4), yang dapat diurai menjadi

$$
\begin{array}{r}
V_{0}=e^{-r n \Delta t} \sum_{j=0}^{k-1}\left(\begin{array}{l}
n \\
j
\end{array}\right) p^{j} q^{n-j} \max \left\{u^{j} d^{n-j} S_{0}-K, 0\right\}+ \\
e^{-r n \Delta t} \sum_{j=k}^{n}\left(\begin{array}{l}
n \\
j
\end{array}\right) p^{j} q^{n-j} \max \left\{u^{j} d^{n-j} S_{0}-K, 0\right\}
\end{array}
$$

dengan $k$ menyatakan tingkat kenaikan harga saham $u$ yang akan menghasilkan

$$
u^{k} d^{n-k} S_{0}-K>0
$$

sehingga

$$
\sum_{j=k}^{n}\left(\begin{array}{l}
n \\
j
\end{array}\right) p^{j} q^{n-j}
$$

merupakan peluang opsi call yang akan berakhir pada in the money, sedangkan peluang opsi call yang berakhir out of the money memberikan hasil

$$
\sum_{j=k-1}^{n}\left(\begin{array}{l}
n \\
j
\end{array}\right) p^{j} q^{n-j} \max \left\{u^{j} d^{n-j} S_{0}-K, 0\right\}=0 .
$$


Maka

$$
\begin{aligned}
V_{0} & =e^{-r n \Delta t} \sum_{j=k}^{n}\left(\begin{array}{c}
n \\
j
\end{array}\right) p^{j} q^{n-j} \max \left\{u^{j} d^{n-j} S_{0}-K, 0\right\} \\
& =S_{0} \sum_{j=k}^{n}\left(\begin{array}{c}
n \\
j
\end{array}\right)\left(p^{*}\right)^{j}\left(q^{*}\right)^{n-j}-e^{-r n \Delta t} K \sum_{j=k}^{n}\left(\begin{array}{c}
n \\
j
\end{array}\right) p^{j} q^{n-j}
\end{aligned}
$$

dengan

$$
p^{*}=e^{-r \Delta t} p u \quad \text { dan } \quad q^{*}=e^{-r \Delta t} q d
$$

Terlebih dahulu perhatikan bagian pertama

$$
\sum_{j=k}^{n}\left(\begin{array}{l}
n \\
j
\end{array}\right)\left(p^{*}\right)^{j}\left(q^{*}\right)^{n-j}=P(J \geq k) .
$$

Bila dilakukan transformasi pada peubah acak $J$

$$
Z=\frac{J-n p^{*}}{\sqrt{n p^{*} q^{*}}}
$$

maka menurut Teorema Limit Pusat untuk $n \rightarrow \infty$ peubah acak $Z$ berdistribusi normal baku $N(0,1)$, sehingga persamaan (4.1) dapat dinyatakan dengan

$$
P(J \geq k)=P\left(Z \geq \frac{k-n p^{*}}{\sqrt{n p^{*} q^{*}}}\right)
$$

dengan

$$
k>\frac{\ln \left(\frac{K}{S_{0}}\right)+n \sigma \sqrt{\Delta t}}{2 \sigma \sqrt{\Delta t}}
$$

sehingga

$$
\begin{aligned}
P(J \geq k) & =P\left(Z \geq \frac{\ln \left(\frac{K}{S_{0}}\right)+\frac{T \sigma}{\sqrt{\Delta t}}\left(1-2 p^{*}\right)}{2 \sigma \sqrt{T p^{*} q^{*}}}\right) \\
& =P\left(Z \geq \frac{\ln \left(\frac{K}{S_{0}}\right)-\left(r+\frac{1}{2} \sigma^{2}\right) T}{\sigma \sqrt{T}}\right) \\
& =N\left(-\frac{\ln \left(\frac{K}{S_{0}}\right)-\left(r+\frac{1}{2} \sigma^{2}\right) T}{\sigma \sqrt{T}}\right) \\
& =N\left(\frac{\ln \left(\frac{S_{0}}{K}\right)+\left(r+\frac{1}{2} \sigma^{2}\right) T}{\sigma \sqrt{T}}\right)
\end{aligned}
$$


Bagian kedua akan diperoleh melalui proses yang sama. Jadi model Black-Scholes opsi call tipe Eropa adalah

$$
\begin{aligned}
V_{0} & =S_{0} \sum_{j=k}^{n}\left(\begin{array}{l}
n \\
j
\end{array}\right)\left(p^{*}\right)^{j}\left(q^{*}\right)^{n-j}-e^{-r n \Delta t} K \sum_{j=k}^{n}\left(\begin{array}{c}
n \\
j
\end{array}\right) p^{j} q^{n-j} \\
& =S_{0} N\left(\frac{\ln \left(\frac{S_{0}}{K}\right)+\left(r+\frac{1}{2} \sigma^{2}\right) T}{2 \sigma \sqrt{T}}\right)-e^{-r n \Delta t} K N\left(\frac{\ln \left(\frac{S_{0}}{K}\right)+\left(r-\frac{1}{2} \sigma^{2}\right) T}{\sigma \sqrt{T}}\right)
\end{aligned}
$$

disederhanakan penulisannya menjadi

$$
V_{0}=S_{0} N\left(d_{1}\right)-K e^{-r T} N\left(d_{2}\right)
$$

Begitu juga dalam menentukan model Black-Scholes opsi put tipe Eropa, sehingga diperoleh

$$
P_{0}=K e^{-r T} N\left(-d_{2}\right)-S_{0} N\left(-d_{1}\right)
$$

dengan

$$
d_{1}=\frac{\ln \left(\frac{S_{0}}{K}\right)+\left(r+\frac{1}{2} \sigma^{2}\right) T}{\sigma \sqrt{T}} \quad \text { dan } \quad d_{2}=\frac{\ln \left(\frac{S_{0}}{K}\right)+\left(r-\frac{1}{2} \sigma^{2}\right) T}{\sigma \sqrt{T}} .
$$

\section{Penerapan Model Black-Scholes Pada Data Harga Saham}

Model Black-Scholes dipengaruhi oleh lima faktor yaitu: nilai volatilitas $\sigma$ harga saham sebesar 0.2296 (diperoleh dari data saham harian Intel Corporation, diakses melalui http://www.finance.yahoo.com pada tanggal 3 Mei 2013), tingkat suku bunga bebas resiko $r$ yang sedang berlaku di Amerika sebesar 0.0025 (diakses melalui http:/www.fxstreet.com/fundamental/interest-rates-table/), waktu jatuh tempo 28 Juni 2013 yang berarti 56 hari lagi dari tanggal 3 Mei 2013 (diperoleh $T=0.15$ ), harga $S_{0}$ yang diperoleh dari data penutupan terakhir, harga $K$ tersedia pada data saham jatuh tempo yang dipilih [2].

Perhitungan harga opsi call model Black-Scholes pada $K=22.00$ dollar :

$$
\begin{aligned}
d_{1} & =\frac{\ln \left(\frac{23.96}{22}\right)+\left(0.0025+\frac{0.053}{2}\right) 0.15}{0.2296 \sqrt{0.15}} & & =\frac{\ln \left(\frac{23.96}{22}\right)+\left(0.0025-\frac{0.053}{2}\right) 0.15}{0.2296 \sqrt{0.15}} \\
& =1.01 & & =0.92
\end{aligned}
$$

Selanjutnya dapat dicari nilai dari $N\left(d_{1}\right)$ dan $N\left(d_{2}\right)$ dengan bantuan perintah NORMSDIST pada software Microsoft Excel. Sehingga nilai opsi call model BlackScholes diperoleh seperti berikut

$$
\begin{aligned}
V_{0} & =(23.96) N(1.01)-22 e^{-0.0025(0.15)} N(0.92) \\
& =2.15
\end{aligned}
$$

Nilai opsi call pada semua harga pelaksanaan akan dibandingkan dengan harga opsi call dipasaran, ternyata harga opsi call pada semua harga pelaksanaan opsi menarik untuk dibeli karena harga opsi call dipasar ternyata berada dibawah harga hitung model Black-Scholes. Begitu juga untuk nilai opsi put, pada semua harga pelaksanaan akan dibandingkan dengan harga opsi put dipasaran. Hasilnya harga 
hitung model Black-Scholes berada diatas harga yang ditawarkan dipasaran, lebih baik pembeli opsi put melaksanakan opsinya, karena semua harga opsi put yang ditawarkan dibawah nilai prediksi kewajaran opsi.

\section{Analisa Laba (Rugi) bagi Pembeli dan Penjual Opsi Saham Tipe Eropa}

Perhatikan tabel berikut.

Tabel 1. Laba (Rugi) Opsi Call (Data harga dalam Dollar)

\begin{tabular}{|c|c|c|c|c|}
\hline $\begin{array}{c}\text { Harga } \\
\text { Pelaksanaan }\end{array}$ & $\begin{array}{c}\text { Harga Opsi Call } \\
\text { di Pasaran }\end{array}$ & $\begin{array}{c}\text { Harga Saham saat } \\
\text { Jatuh Tempo }\end{array}$ & $\begin{array}{c}\text { Laba (Rugi) } \\
\text { Pembeli }\end{array}$ & $\begin{array}{c}\text { Laba (Rugi) } \\
\text { Penjual }\end{array}$ \\
\hline 22 & 1.68 & 24.23 & 0.55 & $(0.55)$ \\
\hline 22.5 & 1.17 & 24.23 & 0.56 & $(0.56)$ \\
\hline 23 & 0.76 & 24.23 & 0.47 & $(0.47)$ \\
\hline 23.5 & 0.36 & 24.23 & 0.37 & $(0.37)$ \\
\hline 24 & 0.15 & 24.23 & 0.08 & $(0.08)$ \\
\hline 24.5 & 0.05 & 24.23 & $(0.05)$ & 0.05 \\
\hline 25 & 0.02 & 24.23 & $(0.02)$ & 0.02 \\
\hline 25.5 & 0.02 & 24.23 & $(0.02)$ & 0.02 \\
\hline 26.5 & 0.01 & 24.23 & $(0.01)$ & 0.01 \\
\hline
\end{tabular}

Pembeli opsi call memperoleh keuntungan maksimum sebesar 0.56 dollar untuk satu lembar saham dan kerugian maksimum yang ditanggung oleh pembeli opsi call sebesar opsi yang telah dibayarkan yaitu 0.05 dollar untuk satu lembar opsi. Sebaliknya bagi penjual opsi call. Sedangkan untuk opsi put adalah sebagai berikut.

Harga pelaksanaan 26.5 dan 28 dollar, pembeli opsi put memperoleh maksimum keuntungan sebesar 0.05 dollar untuk satu lembar saham. Kerugian maksimum yang dapat terjadi pada pembeli adalah sebesar 1.79 dollar. Sebaliknya bagi penjual opsi put. Intel Corporation memiliki strategi yang bagus agar dapat meraih keuntungan besar.

\section{Penutup}

Model harga opsi call dan opsi put tipe Eropa untuk model Black-Scholes diturunkan melalui metode binomial adalah sebagai berikut:

$$
\begin{gathered}
V_{0}=S_{0} N\left(d_{1}\right)-K e^{-r T} N\left(d_{2}\right), \\
P_{0}=K e^{-r T} N\left(-d_{2}\right)-S_{0} N\left(-d_{1}\right),
\end{gathered}
$$

dimana

$$
d_{1}=\left(\frac{\ln \left(\frac{S_{0}}{K}\right)+\left(r+\frac{1}{2} \sigma^{2}\right) T}{\sigma \sqrt{T}}\right) \quad \text { dan } \quad d_{2}=\left(\frac{\ln \left(\frac{S_{0}}{K}\right)+\left(r-\frac{1}{2} \sigma^{2}\right) T}{\sigma \sqrt{T}}\right) .
$$


Tabel 2. Laba (Rugi) Opsi Put (Data harga dalam Dollar)

\begin{tabular}{|c|c|c|c|c|}
\hline $\begin{array}{c}\text { Harga } \\
\text { Pelaksanaan }\end{array}$ & $\begin{array}{c}\text { Harga Opsi Put } \\
\text { di Pasaran }\end{array}$ & $\begin{array}{c}\text { Harga Saham saat } \\
\text { Jatuh Tempo }\end{array}$ & $\begin{array}{c}\text { Laba (Rugi) } \\
\text { Pembeli }\end{array}$ & $\begin{array}{c}\text { Laba (Rugi) } \\
\text { Penjual }\end{array}$ \\
\hline 22.5 & 0.05 & 24.23 & $(0.05)$ & 0.05 \\
\hline 23 & 0.11 & 24.23 & $(0.11)$ & 0.11 \\
\hline 23.5 & 0.27 & 24.23 & $(0.27)$ & 0.27 \\
\hline 24 & 0.45 & 24.23 & $(0.45)$ & 0.45 \\
\hline 24.5 & 0.87 & 24.23 & $(0.87)$ & 0.87 \\
\hline 25 & 1.4 & 24.23 & $(1.4)$ & 1.4 \\
\hline 25.5 & 1.77 & 24.23 & $(1.77)$ & 1.77 \\
\hline 26 & 1.79 & 24.23 & $(1.79)$ & 1.79 \\
\hline 26.5 & 2.22 & 24.23 & 0.05 & $(0.05)$ \\
\hline 28 & 3.75 & 24.23 & 0.02 & $(0.02)$ \\
\hline
\end{tabular}

Berdasarkan hasil perhitungan akan diperoleh hasil laba (rugi) sebagai berikut:

(1) Setelah dihitung laba (rugi) pembeli opsi call pada semua harga pelaksanaan maka keuntungan terbesar yang akan diperoleh adalah 0.56 dollar untuk satu lembar sahamnya. Sedangkan kerugian yang diperoleh penjual opsi call sebesar keuntungan pembeli opsi call. Jadi semakin tinggi harga saham saat dilaksanakan semakin besar keuntungan yang diperoleh pembeli opsi call.

(2) Setelah dihitung laba (rugi) pembeli opsi put pada semua harga pelaksanaan maka keuntungan terbesar yang akan diperoleh adalah 0.05 dollar untuk satu lembar sahamnya. Sedangkan keuntungan yang diperoleh penjual opsi put adalah sebesar 1.79 dollar, padahal pada harga pelaksanaan lebih besar dari harga saham saat opsi jatuh tempo, ini terjadi karena tingginya harga opsi yang ditawarkan oleh Intel Corporation, membuat pembeli opsi put pada harga pelaksanaan 26 dollar tersebut tidak memperoleh keuntungan. Pada umumnya investor pembeli opsi put pada Intel Corporation tidak memperoleh keuntungan. Jadi semakin kecil harga saham saat opsi dilaksanakan dibanding harga pelaksanaan maka semakin besar keuntungan pembeli opsi put.

\section{Ucapan Terima kasih}

Penulis mengucapkan terima kasih kepada Bapak Dr. Dodi Devianto, Ibu Riri Lestari, M.Si, Ibu Hazmira Yozza, M.Si, Ibu Izzati Rahmi, M.Si dan Ibu Dr. Lyra Yulianti yang telah memberikan masukan dan saran sehingga paper ini dapat diselesaikan dengan baik.

\section{Daftar Pustaka}

[1] Bodie Z, Kane A, Marcus AJ. 2005. Investasi.Jilid 1,2. Budi Wibowo. Penerjemah; Salemba Empat. 
Penurunan Model Black-Scholes dengan Metode Binomial 57

[2] Closing price. 2013. Available from: http://www.finance.yahoo.com. [diakses pada 3 Mei 2013].

[3] Halim, A. 2005. Analisis Investasi.Edisi Kedua. Jakarta:Salemba Empat.

[4] Hull, J.C. 2003.Option Future and Other Derivative. University of Toronto: Prentice hall International Inc. 